\title{
CORRECTION
}

\section{Correction: Genetic variants in the MRPS30 region and postmenopausal breast cancer risk}

Ying Huang', Dennis G Ballinger², James Y Dai', Ulrike Peters', David A Hinds², David R Cox², Erica Beilharz², Rowan T Chlebowski ${ }^{3}$, Jacques E Rossouw ${ }^{4}$, Anne McTiernan', Thomas Rohan ${ }^{5}$ and Ross L Prentice ${ }^{1 *}$

\section{Correction}

After publication of this work [1], we noted the following errors in describing the genotype of rs7705343. In Table 3 of the main text and Table S3 of the supplementary material, SNP genotype names GG and AA need to switch order. Also, the GG genotype should be the AA genotype in the fifth paragraph of the Results and the fifth paragraph of the Discussion.

\section{Author details}

'Fred Hutchinson Cancer Research Center, 1100 Fairview Avenue N, M3-A410, POB 19024, Seattle, WA 98109-1024, USA. 2 Perlegen Sciences Inc., 2012 Stierlin Court, Mountain View, CA 94043, USA. ${ }^{3}$ Harbor-UCLA Research and Education Institute, 1124 W. Carson Street, Bldf J-3, Torrance, CA 90502-2064, USA. ${ }^{4}$ National Institutes of Health, 6701 Rockledge Drive, Bethesda, MD 208927935, USA. ${ }^{5}$ Albert Einstein College of Medicine, 1300 Morris Park Avenue, Bronx, NY 10461, USA.
Published: 12 March 2012

\section{Reference}

1. Huang Y, Ballinger DG, Dai JY, Peters U, Hinds DA, Cox DR, Beilharz E, Chlebowski RT, Rossouw JE, McTiernan A, Rohan T, and Prentice RL. Genetic variants in the MRPS30 region and postmenopausal breast cancer risk. Genome Medicine 2011, 3:42. doi:10.1186/gm318

Cite this article as: Huang Y, et al:: Correction: Genetic variants in the MRPS30 region and postmenopausal breast cancer risk. Genome Medicine 2012, 4:19.

Full list of author information is available at the end of the article 